THE U.S. METEOROLOGICAL STATION AT POINT BARROW.'

The U. S. expedition to Point Barrow, Alaska, sent out under the auspices of the Signal-service in 1881 , was one of the International polar expeditions determined upon by the International polar congress, which met in Hamburg in October, 1879, and was designed to co-operate with the various stations established around the north pole in simultaneous observations in the three elements of magnetism and in meteorology. Nearly the whole civilized world was represented in this work; and, commencing with the Greely party at Lady Franklin Bay, they posted their chain of videttes around the pole in the following order: Denmark, Upernavik and Godthaab ; Germany, Pendulum Island; Austria, Iceland and the Island of Jan Majen ; Sweden, Mosel Bay, on
Holland, Dickson Haven ; United States, Point Barrow and Lady Franklin Bay. The series of international observations proper was to commence Aug. 1, 1882, and end Aug. 31, 1883.

The little colony for Point Barrow, consisting of ten persons in all, sailed from San Francisco, Cal., in the schooner Golden Fleece, on the 18th of July, 1881, and, after a long, monotonous voyage across the North Pacific, passed into Bering Sea, through the Unimak Pass, on the 15th of August, and after touching at Plover Bay, Siberia, to correct the rate of their chronometers by observation on that well-established meridian, passed through Bering's Strait on the twenty-seventh day of August, and reached their destination on the 8th of September, fifty-one days out from San Francisco. The vessel returned to the United States at once, after discharging her cargo.

The energies of the party were at first en-

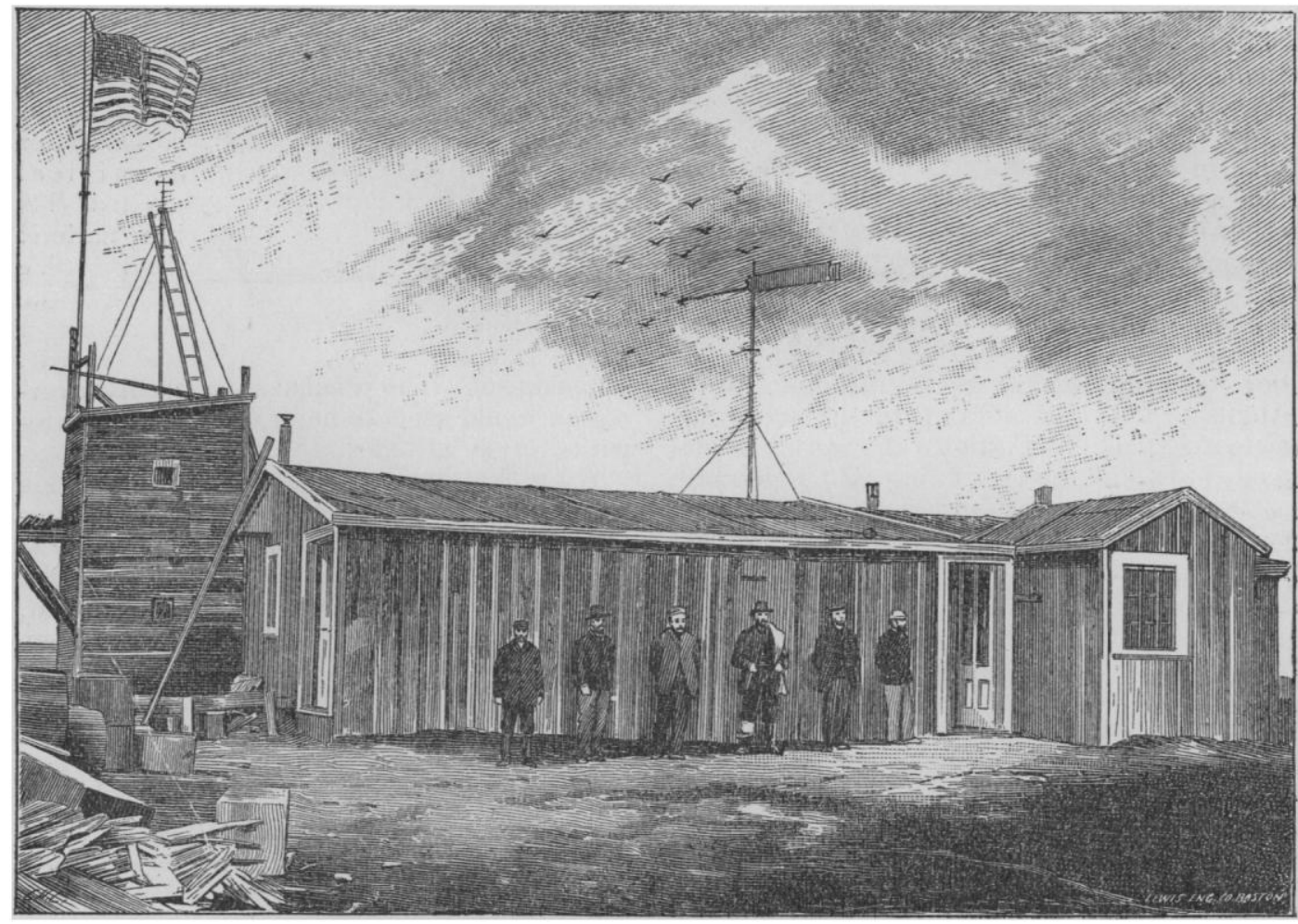

SIGNAL-8TATION AT POINT BARROW, ALASKA UNITED.STATES.

West Spitzbergen ; Norway, Bossekop ; Finland, Sodankyla; Russia, Moller Bay, on Spitzbergen, and at the mouth of the Lena;

1 Communicated by permission of Gen. W. B. Hazen, chief signal-officer. tirely devoted to housing themselves for the winter, and securing their stores; and the 1st of October found them with the building nearly completed, observatories up, and with three year's' supplies well secured, in a condition to 
look the future very confidently in the face. The instruments were placed, and hourly observations in meteorology commenced, on Oct. 17 , and in magnetism on Dec. 1 ; and this work was carried on without a single interruption from that time up to the last hour the sta- at the depth of twenty-six feet, which was fourteen feet below the sea-level, was found a pair of wooden snow-goggles of the same pattern as those worn now, showing that this region has been inhabited by man for a longer period than has generally been supposed by

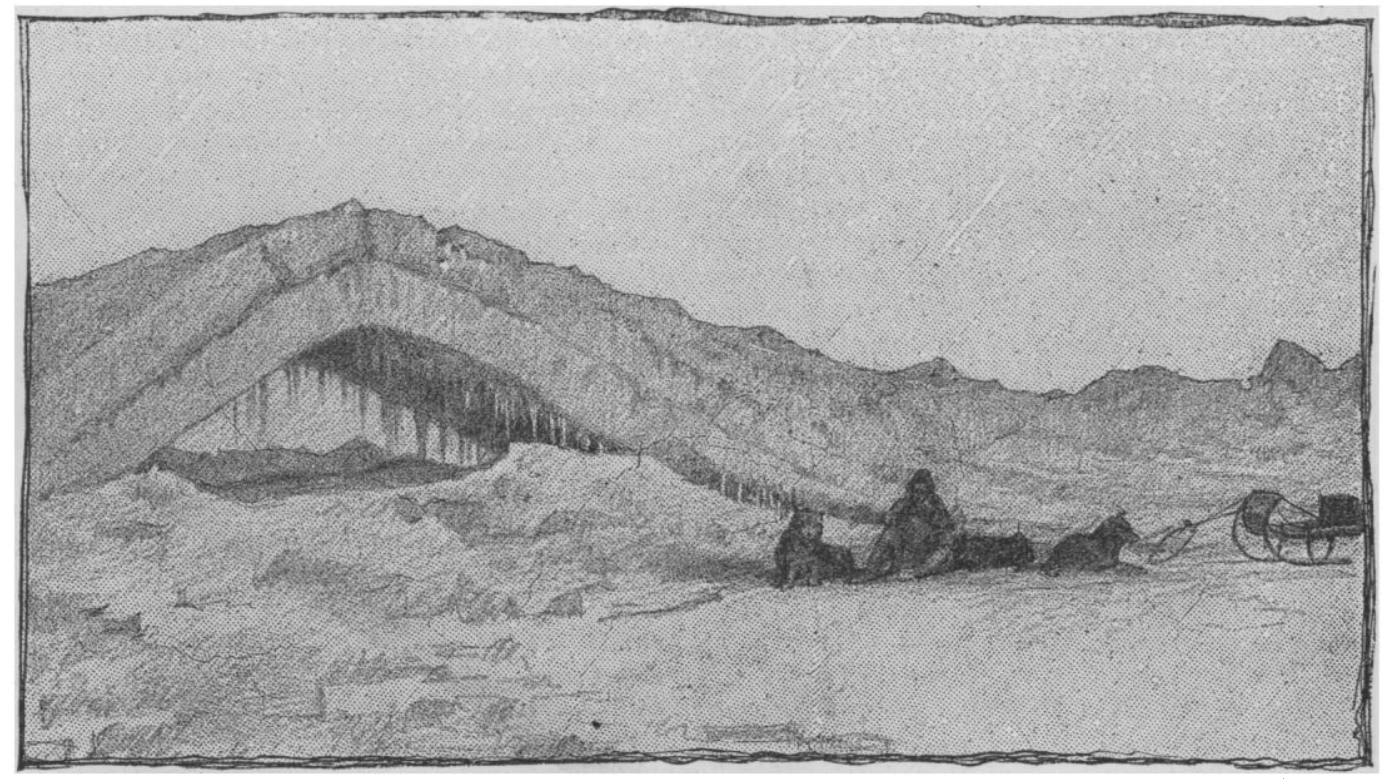

ICE-ARCH FORMED NEAR POINT BARROW.

tion was occupied, on the twenty-ninth day of August, 1883. In addition to the prescribed meteorological observations, the work was extended to taking and recording the temperature of the sea-water, top and bottom, the sea-ice, and the earth, and measuring the terrestrial and solar radiation.

The auroral display of this region was grand beyond all description; and nearly every unclouded night from September to May was lit up with the dancing light of this strange phenomenon; and, when shut from our view by the clouds, the disturbed needle told of its presence.

The tidal record shows that the adjacent ocean is almost tideless ; and that there is no influx of warm water from the Japan current or elsewhere was shown in the even temperature of the sea-water at all depths, from October to June.

The earth was found to be frozen to an immense depth. 'The temperature at thirty-eight feet (the lowest depth attained) was $+12^{\circ} \mathrm{F}$., and the ratio of increase of temperature for that distance gives the depth of the frost to be nearly three hundred feet. At the lower depths attained, the temperature never changes; and ethnologists. The peculiar race inhabiting this region would seem to be indigenous to the ice period in all latitudes.

After November we found that all animal life disappears from the land; and, except for an occasional stray reindeer or white fox, we saw no living thing but the Innuit and his dog from November until May, and the sea gave us only the arctic cod and small hair seal (Phoca foetida).

Lying between us and the pole was a sea of eternal ice, which we believe is an impassable barrier between us and latitude $90^{\circ}$ north : over its rough and broken surface it is impossible to travel with any known means of transportation. Unencumbered and on foot is the only manner in which man can penetrate this unknown world: so the distance he can travei is limited to the number of days he can carry supplies on his back, or by the slow process of floating; and nature is ever crowding him back, even where the current sets to the north in her process of restoring her equilibrium at the pole. We found from long, careful observations, that the maximum thickness of sea-ice over still 
water was about seren feet; but, owing to the influence of gales and currents, the whole ocean is filled with pack from fifty to two hundred feet in thickness. During the whole winter this region is subject to violent local gales, which open huge cracks in this frozen ocean, often extending many miles, and from ten to five hundred yards wide. These cracks freeze over very rapidly, as the temperature of the sea-water alway stands at $29.2^{\circ} \mathrm{F}$. We have known two feet and a half of ice to be formed over one of these cracks in ten hours. This expansion, acting like a great wedge, shoves the great masses of pack apart; and it can only find room in the direction of the lower latitudes, or side of the least resistance. Hence we see along the southern edge of the eternal pack a continual crowding-down of old ice, which has yielded to the new ice formed in the cracks, and, in its turn, is packed and displaced; but we never found that there was any accumulation of new ice on the submerged masses of old pack, no matter to what depth they rested in the water. This process going on daily and hourly, the ice over the pole is kept at an even thickness ; the old, heavy ice, often high above the surface, yielding to the new. We never found that ice formed on the bottom of the sea, the lakes, or the rivers.

The migration of the eider occurs in May; and the flight is to the north-east, in the direction of Prince Patrick's Land. 'We never saw any flight of birds to or from true north at any season of the year. 'They commence returning' along the western shore in July, and linger as long as there is any open water.

The members of the expedition found time to make a large collection in ethnology and natural history, which has been turned over to the Smithsonian institution, and is now being catalogued and placed. All records were kept in duplicate, and both copies were brought safely back to the United States. The official report is now being compiled at Washington, and will be issued by the signal-office as soon as published.

The party returned to the United States on the schooner Leo, chartered for that purpose ; leaving the station Aug. 29, 1883, and returned viâ Bering Strait and the Pass of Akutan, landing at San Francisco, Cal., Oct. 7, 1883; touching only at St. Michael's, where Lieut. Schwatka and his party were found waiting for a chance to return to the United States, after their adventurous ride of over two thousand miles down the Yukon on a raft, and at Unalaska, to repair our little vessel, which had been damaged by the ice.

P. H. RAY.

\section{ON THE STATE OF THE INTERIOR OF THE EARTH.}

The appearance of the new edition of Thomson and Tait's treatise on natural philosophy affords an opportunity for geologists to object to conclusions reached by physicists in relation to the condition of the interior of the earth. Various physicists, chief among whom are Hopkins, Sir William Thomson, and G. H. Darwin, have concluded, from a discussion of the phenomena of precession and of tidal friction, that the earth is a solid, with a rigidity at least as great as steel. Some time ago Thomson retracted the first part of the argument, on a suggestion made by Newcomb, and the writer expected to see a retraction of the entire argument in the new edition of the philosophy; but it does not appear. Yet the statement is somewhat modified. On the 485th page of rol. i., part ii., the following paragraph appears : -

"These conclusions, drawn solely from a consideration of the necessary order of cooling and consolidation, according to Bischof's result as to the relative specific gravities of solid and of melted rock, are in perfect accordance with $\S \S 832-848$, regarding the present condition of the earth's interior, - that it is not, as commonly supposed, all liquid within a thin solid crust of from 30 to 100 miles thick, but that it is, on the whole, more rigid, certainly, than a continuous solid globe of glass of the same diameter, and probably than one of steel."

It is not my purpose as a geologist to discuss the methods by which this conclusion is reached; nor shall I array the facts by which geologists arrive at a different conclusion. I propose simply to characterize the lines of inductive reasoning used by them. These are as follows :-

\section{The argument from displacement.}

The writer has carefully studied a fault in Utah and Arizona, about three hundred miles in length, with a throw varying from two thousand to five thousand feet. Everywhere along its course the displacement is easily seen : its verity is a fact of observation, confirmed by the observation of other geologists thoroughly competent. The fault is so plain, that the tyro in geology may see it. Now, in the case of this fault, three hypotheses may be entertained, - first, that the thrown side subsided; second, that the thrown side remained stationary in relation to the centre of the earth, and the opposite side was upheared; or, third, that 